\title{
Analysis of a Drive Shaft for Automobile Applications
}

\author{
P. Jayanaidu ${ }^{1}$, M. Hibbatullah ${ }^{1}$, Prof. P. Baskar ${ }^{2}$ \\ 1. $P G$, School of Mechanical and Building Sciences, VIT University, India \\ 2. Asst. Professor, School of Mechanical and Building Sciences, VIT University, India
}

\begin{abstract}
This study deals with optimization of drive shaft using the ANSYS. Substitution of Titanium drive shafts over the conventional steel material for drive shaft has increasing the advantages of design due to its high specific stiffness, strength and low weight. Drive shaft is the main component of drive system of an automobile. Use of conventional steel for manufacturing of drive shaft has many disadvantages such as low specific stiffness and strength. Many methods are available at present for the design optimization of structural systems. This paper discusses the past work done on drive shafts using ANSYS and design and modal analysis of shafts made of Titanium alloy (Ti-6Al-7Nb).
\end{abstract}

Keywords: Drive Shaft, ANSYS, Titanium, Stiffness.

\section{Introduction}

An automotive drive shaft transmits power from the engine to the differential gear of a rear wheel drive vehicle. The drive shaft is usually manufactured in two pieces to increase the fundamental bending natural frequency because the bending natural frequency of a shaft is inversely proportional to the square of beam length and proportional to the square root of specific modulus which increases the total weight of an automotive vehicle and decreases fuel efficiency. So, a single piece drive shaft is preferred here and the material of it is considered to be Titanium alloy because of its high strength and low density. Drive shafts are carriers of torque and are subject to torsion and shear stress, equivalent to the difference between the input torque and the load. They must therefore be strong enough to bear the stress, whilst avoiding too much additional weight as that would in turn increase their inertia.

\section{1) Purpose of the Drive Shaft (Or Propeller Shaft)}

The torque that is produced from the engine and transmission must be transferred to the rear wheels to push the vehicle forward and reverse. The drive shaft must provide a smooth, uninterrupted flow of power to the axles. The drive shaft and differential are used to transfer this torque.

\section{2) Functions of the Drive Shaft}

a) First, it must transmit torque from the transmission to the differential gear box.

b) During the operation, it is necessary to transmit maximum low-gear torque developed by the engine.

c) The drive shafts must also be capable of rotating at the very fast speeds required by the vehicle.

d) The drive shaft must also operate through constantly changing angles between the transmission, the differential and the axles. As the rear wheels roll over bumps in the road, the differential and axles move up and down. This movement changes the angle between the transmission and the differential.

e) The length of the drive shaft must also be capable of changing while transmitting torque. Length changes are caused by axle movement due to torque reaction, road deflections, braking loads and so on. A slip joint is used to compensate for this motion. The slip joint is usually made of an internal and external spline. It is located on the front end of the drive shaft and is connected to the transmission.

Now days all automobiles (which are having front engine rear wheel drive) have the transmission shaft as shown in figure. A pair of short drive shafts is commonly used to send power from a central differential, transmission, or transaxle to the wheels. Two piece drive shaft increases the weight of drive shaft which is not desirable in today's market. Many methods are available at present for the design optimization of structural systems and these methods based on mathematical programming techniques involving gradient search and direct search. The reduction in weight of the drive system is advantageous in overall weight reduction of automobiles which is a highly desirable goal of design engineer. 

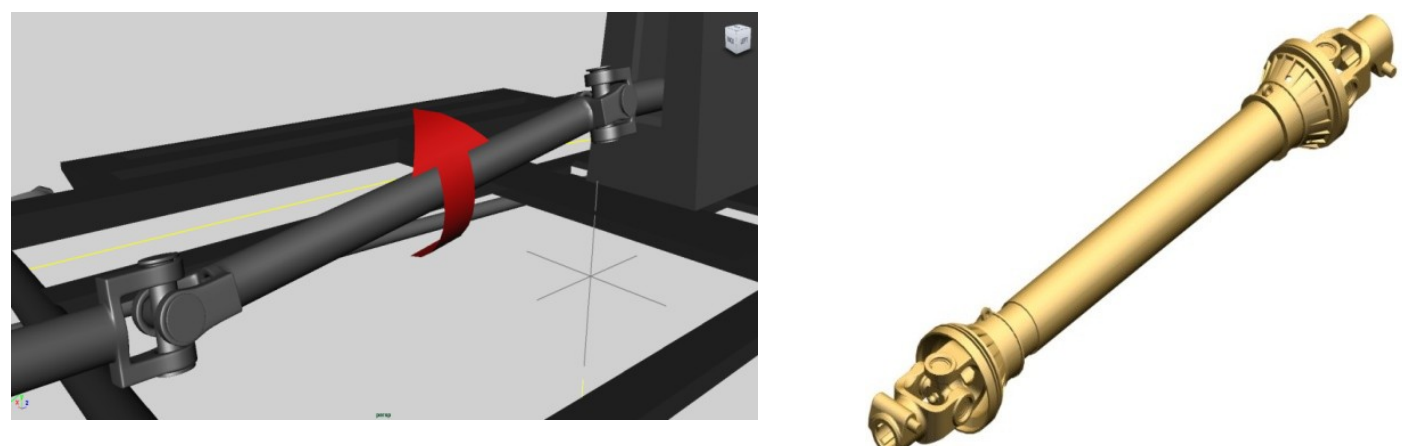

Fig 1: (a) 3D model of a drive shaft \& (b) Position of Drive Shaft

In the present work the focus is given on the replacement of the conventional steel drive shaft by the High Strength and low weight Titanium alloy Ti-6Al-7Nb. A single piece Titanium drive shaft was designed and analyzed using the ANSYS 14.5. Its modal analysis was also done using ANSYS Workbench. This paper also discusses the past work done on steel drive shafts.

2.1) Design Parameters:

\section{Modal And Design Analysis}

The design parameters for the shaft were taken from the journal (1):

\begin{tabular}{|l|l|l|l|}
\hline Parameter of the shaft & Symbol & Value & Unit \\
\hline Outer Diameter & $\mathrm{D}_{\mathrm{o}}$ & 90 & $\mathrm{Mm}$ \\
\hline Inner Diameter & $\mathrm{D}_{\mathrm{i}}$ & 83.36 & $\mathrm{Mm}$ \\
\hline Length & $\mathrm{L}$ & 1250 & $\mathrm{Mm}$ \\
\hline
\end{tabular}

\section{2) Assumptions:}

1. The shaft rotates at a constant speed about its longitudinal axis.

2. The shaft has a uniform, circular cross section.

3. The shaft is perfectly balanced, i.e., at every cross section, the mass center coincides with the geometric center.

4. All damping and nonlinear effects are excluded.

5. Acoustical fluid interactions are neglected, i.e., the shaft is assumed to be acting in a vacuum.

6. Since lamina is thin and no out-of-plane loads are applied, it is considered as under the plane stress.

\section{3) Modeling, Meshing and Boundary conditions for Design Analysis:}

The model was created by using the given parameters in PRO/E and was exported to ANSYS LS-

DYNA using “.iges" format. Thin Shell 180 was considered as the element type and material properties were given for both Steel and Titanium separately. Then meshing was done for areas using Quad meshing. After this the shaft is fixed at one end and torque is applied at other end. By considering that the shaft rotates at $3000 \mathrm{rpm}$ (1), the angular velocity becomes 50rps. Then the model is solved and FEA results are plotted.

\section{4) Modal Analysis:}

Same steps were followed for Modal Analysis except for it was imported to ANSYS Workbench and total deformations were found out using the Modal

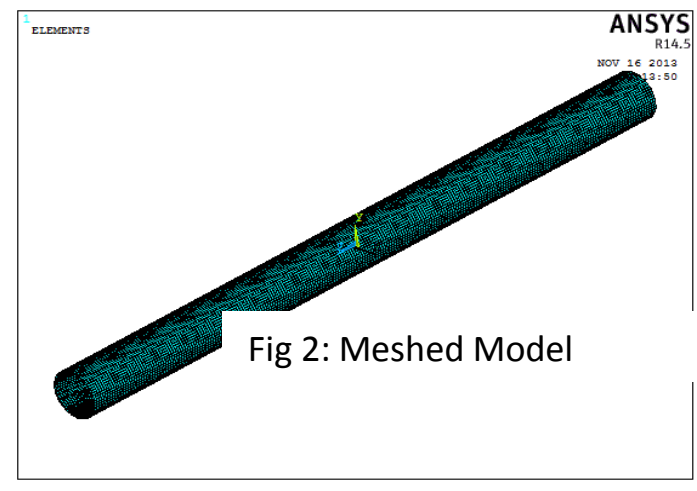
Analysis at 2 different mode values.

\section{Findings Of Finite Element Analysis}

In the following analysis Titanium and steel shafts were compared with each other in terms of their deformation, maximum Shear stress and Von-Mises stress under same conditions as in the previous journal [1]. The Maximum stress undergone and the total deformation occur in Steel under the given conditions. Titanium is better in terms of maximum stress and deformation as these parameters produced in this shaft are less when compared to steel. 

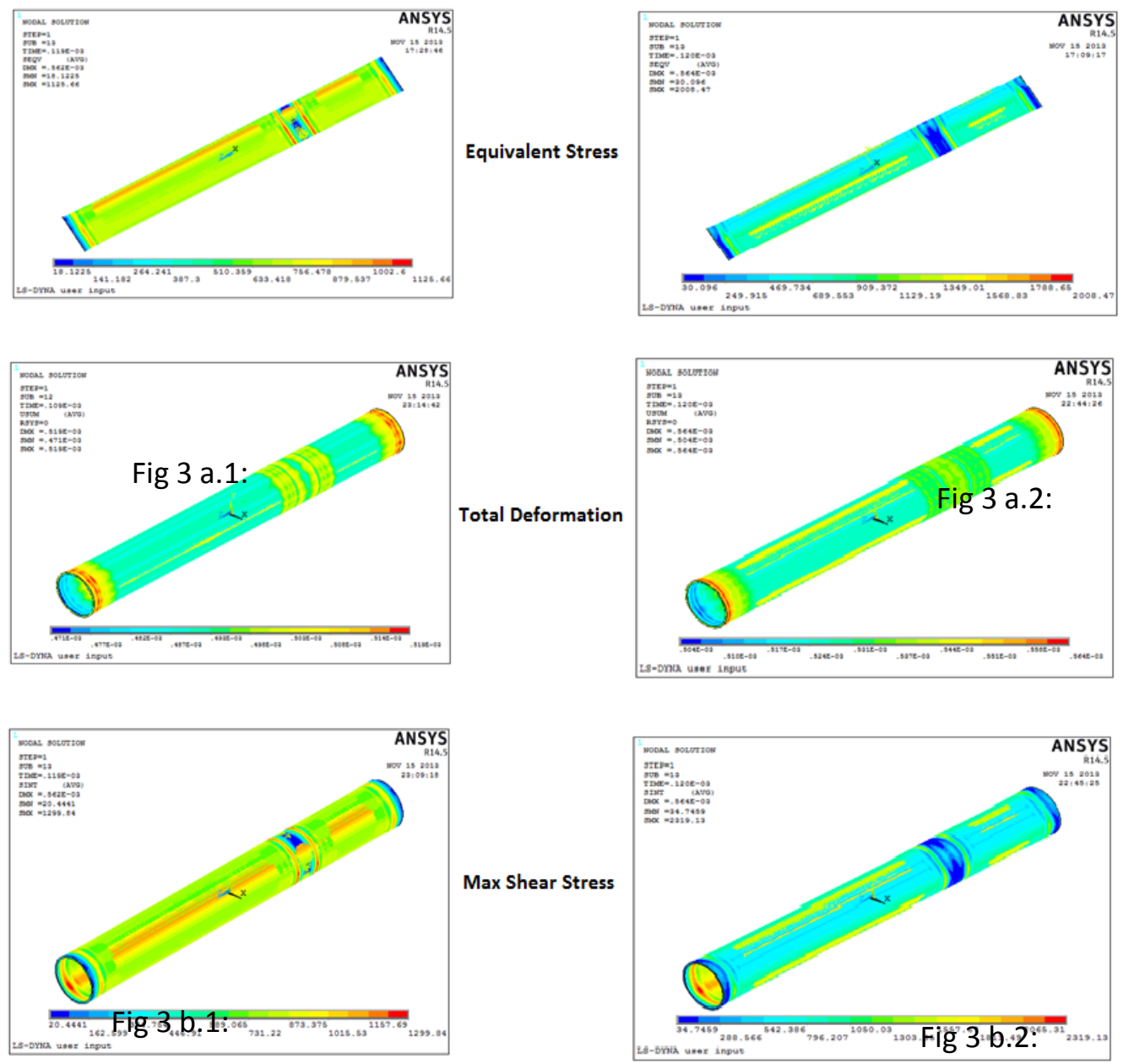

TITANIUM Ti-6AI-7Nb

STEEL

\section{Findings Of Modal Analysis}

The maximum stress point and dangerous areas are found by the deformation produced during the modal analysis of Propeller Shaft. The relationship between the frequency and the vibration modal is explained by the modal analysis of Propeller Shaft. The simulation results show that the frequency increases from first mode shape to second mode shape. The minimum frequency was found in first mode shape i.e. $55.021 \mathrm{~Hz}$ and minimum deformation occurs in the Second mode shape at a frequency of $55.065 \mathrm{~Hz}$. The resonance vibration of system can be avoided effectively by appropriate structure design. The results provide a theoretical basis to optimize the design and fatigue life calculation.
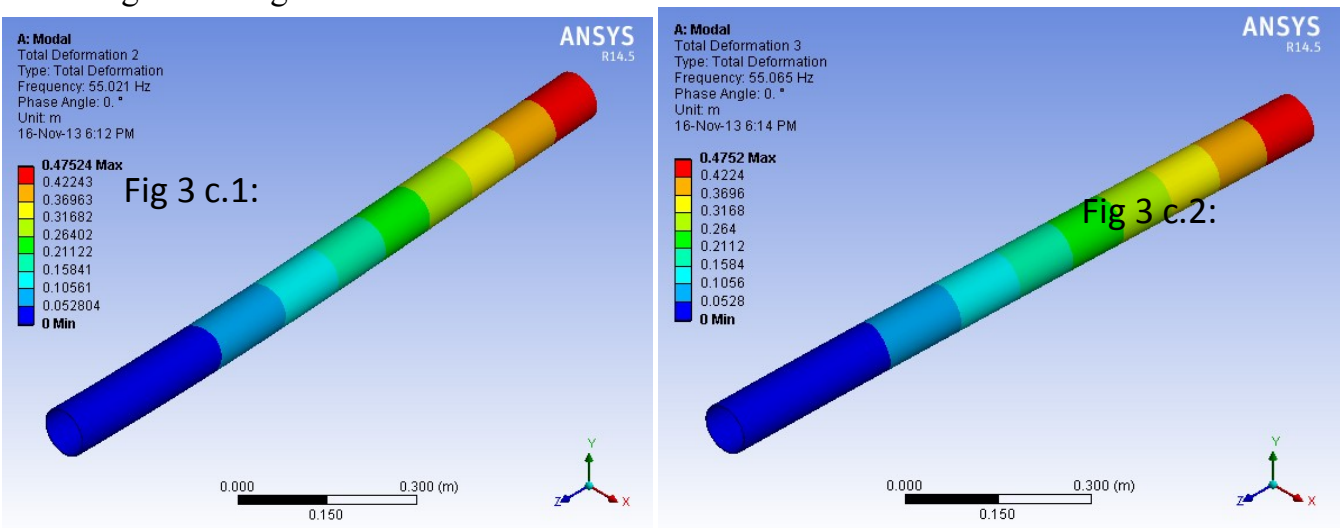

Fig 4: (a) mode at $55.021 \mathrm{~Hz} \&$ (b) mode at $55.065 \mathrm{~Hz}$ 


\begin{tabular}{|c|c|c|}
\hline S.No & Mode & Damped Frequency $[\mathrm{Hz}]$ \\
\hline 1 & 1. & 55.021 \\
\hline 2 & 2. & 55.065 \\
\hline
\end{tabular}

\section{Conclusions}

1. The replacement of conventional drive shaft results in reduction in weight of automobile.

2. The finite element analysis is used in this work to predict the deformation of shaft.

3. The results of the work are encouraging and suggest the replacement of conventional drive shaft made of steel with Titanium alloy.

4. The Total deformation of Steel, Titanium (Ti-6Al-7Nb) was found to be $0.000564 \mathrm{~mm}$ and $0.000519 \mathrm{~mm}$ respectively pointing that Titanium alloy is better than the conventional steel.

5. The relationship between the frequency and the vibration modal is explained by the modal analysis of Propeller Shaft.

6. This work presented a method to calculate the natural frequency of a propeller shafts.

7. The results obtained from this model is an useful approximation to help in the earlier stages of the development, saving development time and helping in the decision making process to optimize a design, before going into a detailed finite element analysis.

\section{References}

[1] Sagar. R. Dharmadhikari, Sachin. G. Mahakalkar, Jayant P Giri, Nilesh D Khutafale "Design and Analysis of Composite Drive Shaft using ANSYS and Genetic Algorithm" IJMER Jan-Feb. 2013, pp-490-496.

[2] Felipe Moura Fontes Novo, Mauro Moraes de Souza, Juliano Savoy, Marcelo Adriano do Carmo Silva, "Analysis of the vibration modes of an automotive propeller shaft using FEM and analytical models" SAE-2012-36-0224

[3] A. M. Ummuhaani, Dr. P. Sadagopan, "Design, Fabrication and Stress Analysis of a Composite Propeller Shaft" SAE- 2011-28-0013. 